\title{
HOIAKUD TÕLKIMISE KOHTA EHK KUIDAS DEFINEERITAKSE TÕLKIMIST
}

\author{
TRIIN VAN DOORSLAER
}

$\mathrm{A}$ rusaamine sellest, mida tõlkides tehakse või mida kujutab endast tõlkeprotsess, on olnud juba pikemat aega tõlkeuuringute huviorbiidis. Tõlkimise kohta on välja kujunenud teatud hoiakud ja ka tõlketeadus oma praegusel kujul, alates 1970. aastatest, hoiab endas arvutult metafoore ning definitsioone, mis erinevad üksteisest palju, kuid millest ükski ei pretendeeri ainuõige või läbinisti vale tiitlile.

1960.-1970. aastatel oli olukord tõlkimise defineerimisel lihtsam. „Tõlkimist määratleti peamiselt ekvivalentsusteooriate abil ja tõlketeaduse eesmärk oli nimetatud ekvivalentsussuhete modaalsuse kirjeldamine" (Pym 2007: 154). ${ }^{1}$ Ekvivalentsusteooriaid on erinevaid, kuid neid kõiki ühendab eeldus, et lähte- ja sihtteksti vahel peab olema selge ühisosa (Panou 2013). Milline see ühisosa täpselt olema peaks, on tekitanud vaidlusi, kuid levinuim lähenemine on nn sõnasõnaline versus $\mathrm{nn}$ vaba tõlge, kus sõnasõnalisust võib omakorda defineerida kui kahe keelepaari vahelist vastavust, mille aluseks on näiteks kakskeelse sõnaraamatu vasted (vt ka Vinay, Darbelnet 1995). Juba pikemat aega on tõlketurg ja tõlkimise töömeetodid kiires ning pidevas muutumises. Ekvivalentsusteooriad ei aidanud ühel hetkel enam lahendada tõlkijate probleeme muutuval tõlkemaastikul. Andrew Chesterman on isegi väitnud, et ekvivalentsusteooriatest lähtumine viitab sellele, et tõlkimine on võimatu. „Defineerides tõlkimist ekvivalentsuse kaudu, ja kuna ekvivalentsus on tabamatu, peaks tõlkimine olema võimatu. Teisisõnu: ekvivalentsus eeldab perfektsust ja tegelikkuses on perfektsus tabamatu" (Chesterman 1997: 10). ${ }^{2}$

Tõlkemaastik tingis uute ning sobivamate teoreetiliste lähenemiste vajaduse ning nimelt selliste, mis aitaks tõlkeprotsessi paremini mõtestada. Üks levinumaid on skopos-teooria. Tegemist on ühe esimese funktsionaalse tõlketeooriaga, mille loojad on Katharina Reiss ja Hans Vermeer. Nad eeldavad, et igal tõlkel on alati skopos ehk eesmärk, isegi juhul kui skopos ei ole esmapilgul üheselt selge (Reiss, Vermeer 1984: 21). Funktsionalistid näevad tõlkimist alati eesmärgipärase tegevusena ning tõlke eesmärk peaks olema kajastatud tõlketööga kaasas olevas tõlkeülesandes (ingl translation brief).

Christiane Nord on selgitanud tõlkeülesande vajalikkust sellega, et teksti tähendust või funktsiooni ei ole võimalik välja lugeda lingvistilistest märkidest ja teksti muudab tähenduslikuks vaid lugeja. Erinevad lugejad, või sama lugeja erineval ajahetkel, võivad ühte ja sama lingvistiliste märkide kogumit

\footnotetext{
${ }^{1}$ Ingliskeelsed tsitaadid tõlkis eesti keelde artikli autor.

"Translation was then defined by equivalence, and the task of Translation Studies was to describe the modalities of that relation" (Pym 2007: 154).

2 „If translation is defined in terms of equivalence and since equivalence is unattainable, translation must be impossible. Alternatively: equivalence is, by definition, perfect; but perfection, in practice, is unattainable" (Chesterman 1997: 10).
} 
mõista täiesti erinevalt (Nord 2001: 31). Seetõttu on tõlke eesmärgi selgitamine tõlkijale vajalik, et teada, mida temalt täpsemalt oodatakse. Professionaalsed tõlkijad rõhutavad tõlkeülesande olulisust, näiteks on pikaajaline tõlkija ja toimetaja Andres Valdre (2004: 196) analüüsinud tõlkevigu ning toonud välja, et puudulikust või arusaamatust tõlkeülesandest tingitud vead puudutavad tõlget tervikuna.

Funktsionaalsete teooriate kõrvale tekkisid ka kognitiivsed ehk tunnetuslikud tõlketeooriad, mille kohaselt muutus lisaks tekstile, sõnumi vahendamisele ja tõlke funktsioonile oluliseks tõlkija isik. Kognitiivsed tõlketeooriad toetuvad tunnetuspsühholoogiale ja uurivad tõlkija käitumise erinevaid aspekte tõlkeprotsessi ajal, näiteks ebakindlust, ettetulevate probleemide lahendamist (Angelone 2010) ja tähenduse konstrueerimist (Hatzidaki 2007). Eestis on samuti uuritud kognitiivsete lähenemiste kasutamist tõlkimises, seda ka tõlkijahariduses. Katrin Kask uuris, kuidas muuta tõlkeprotsessi tulemuslikumaks. „Autor oletas, et üheks oluliseks teguriks, mida seni pole tõlkimisega eriti seostatud, võiks olla ka tõlkija õppimis- ja tajumisstiil, eeskätt see, kas tõlkija tajub maailma piltides või sõnades, mis nõuab mõnevõrra erinevaid infotöötlusstrateegiaid” (Kask 2011: 83). Kask jõudis järeldusele, „et visuaalruumilisusega seotud tugevusi ei teadvustata, ometi võiks nende teadvustamine ja sellesuunaliste kognitiivsete tõlkestrateegiate teadlikum kasutamine tõlkeüliõpilaste puhul kasuks tulla" (2011: 83). Kask on välja toonud ühe olulise teema tõlkijahariduses, millega ei ole kuigi palju tegeldud. Kuid on veel terve hulk aspekte, mida tuleks tõlkijahariduses arvesse võtta ning mille teadvustamine tuleb tõlkijatöös kasuks.

Eelnimetatud lähenemistele lisaks on tõlkimise juures hakatud rääkima ka kommunikatiivsest aspektist. Esialgu lähtutakse küll ainult üldistest kommunikatsiooniteooriatest, kuid kommunikatiivse aspekti uurimise vajalikkust tõlketeaduses peetakse üha olulisemaks (Valdeón 2010). Ühest küljest nähakse tõlkijat kui kultuuridevahelise kommunikatsiooni eksperti, kuid kommunikatiivsete lähenemiste alla võib liigitada ka Arvi Tavasti ja Marju Taukari instrumentalistliku tõlkemudeli, mille kohaselt tõlkija on suhtlustaotlust realiseeriv inimene, mitte tekste teisendav mehhanism (Tavast, Taukar 2013: 174).

\section{Ettekujutus tõlkimisest tõlkijahariduses}

Tõlkijakoolituse ja tõlkijahariduse kohta on viimastel aastatel ilmunud hulgaliselt artikleid ja uurimusi, millest paljud on keskendunud tõlkeõppekavade väljatöötamisele, moodulitele ja spetsiifilistele oskustele, nagu lingvistiline kompetents, tõlketarkvara kasutamine, tekstianalüüs jne. Harvemini on käsitletud, milliste probleemidega seisavad silmitsi tõlkeõppejõud. Ehkki tõlkimise õpetamisel ei ole enamasti kasutusel õppejõukeskne lähenemine ning laialt on võetud omaks (näiteks Tallinna Ülikooli kirjaliku tõlke magistriõppe programmis) sotsiokonstruktivistlik lähenemine (vt Kiraly 2000), tuleb tõlkeõppejõududel uute tudengite ees seistes leida vastus paljudele küsimustele. Üks neist on: milline on värskete tõlketudengite ettekujutus ja arusaam tõlkimisest kui protsessist, tõlkimisest kui professionaalsest tegevusest?

Maria Gonzáles Davies on välja toonud järgmised olulised küsimused: kas tudengid oskavad näha erinevust ilukirjandustõlke ja mitteilukirjandusliku 
tõlke vahel? Millised on tudengite $a$ priori eeldused? Lisaks on tõlkija haridustee alguses määrava tähtsusega muutujad, nagu tudengite vanus, elukogemus, taustateadmised ja maailmataju, arvamus tõlkimisest (Gonzáles Davies 2004: 72).

Tallinna Ülikooli kirjaliku tõlke magistriprogrammi on olnud tavaks alustada igal sügisel aruteluga selle üle, mis on tõlkimine ja kuidas uued tudengid tõlkimist mõistavad. Analüüsi eesmärgiks on püstitada küsimused, mida tudengid püüaksid läbivalt oma õpingute jooksul mõtestada, ning luua tõlkimisest iseenda jaoks mingi kontseptsioon. Üks vahend selleks on õpipäevik. Olen varasemalt uurinud, kas õpipäeviku pidamine ja tõlkeprotsessi analüüsimine sellisel kujul aitab kaasa tõlkijategevuse mõtestamisele. Tulemused näitasid, et tudengid hindasid õpipäevikute pidamise kasulikuks ja osaliselt aitas see kaasa tõlkimise defineerimisele ja oma tõlkeprotsessi paremale teadvustamisele (Pappel, Falk 2012). Lisaks õpipäeviku pidamisele toimuvad tõlkimise kontseptsiooni arutelud seminarides, kus tudengitel on võimalus analüüsida tõlkimisel ettetulevaid probleeme, lahata leitud lahendusi ning olla enesekriitiline.

Tõlkimise kontseptsiooni üle arutades on tähtis, et tudengid teadvustaksid kahte aspekti:

a) tõlkeprotsess on sama oluline kui tõlketulemus;

b) tõlkevabaduse määravad erinevad tegurid, nagu näiteks tõlkeülesanne (Gonzáles Davies 2004: 73).

Don Kiraly on väitnud, et tõlkijahariduse keskseks eesmärgiks on tõsta tõlketudengite enesekindlust, ning soovitanud kasutada tõlkijahariduses mitmeid sotsiokonstruktivistlikke põhimõtteid, näiteks:

a) väärtuslikemad õpikogemused on seotud perspektiivide paljususega, mitte ühe ja ainsa tõe ülekandmisega;

b) iga loengu eesmärk peaks olema arvukate ja eluliste (kuid mitte nn õigete) lahenduste leidmine probleemidele, mis autentsete tõlkeprojektide käigus tekivad iseenesest;

c) selle asemel et õpetada tudengitele nn õigeid vastuseid (või nn ainukest tõde), peaks õppejõu ülesanne olema suunav toestamine, pakkuda kursuse algusest alates tudengitele piisavat tuge teadmiste konstrueerimisel ja anda kontroll õpikeskkonna üle pikkamööda tudengitele endile (Kiraly 2000: 65-69).

Nimetatud mustrite jälgimine ning koos tudengitega tõlkimise mõtestamise ja defineerimise üle arutlemine on väga kasulik ka õppejõududele, sest just nii on võimalik saada teada, millised on algajate tõlkijate arusaamad, ideed ning ootused tõlkimisele.

\section{Hoiakud tõlkimise kohta}

Tõlkimist võib pidada mitmetahuliseks ja keeruliseks tegevuseks. Ühelt poolt mängib rolli tõlkija elukogemus ja andekus, teiselt poolt on igas kultuuris tekkinud oma hoiakud või traditsioonilised arusaamad sellest, mis on tõlkimine, mida tõlkija tõlkides teeb või milliseid oskusi on tõlkimiseks vaja. Niisugused arusaamad ei tugine tavaliselt inimese enda kogemusele, vaid on eelarvamused või hoiakud, mis on lihtsalt meie kollektiivse mälu osa. 
Tõlkimise kohta võib üsna kindlalt väita, et meid kõiki mõjutab mingil määral traditsiooniline ja üldine arusaam tõlkimisest kui sellisest. Nagu märgitud, selline vaade tõlkimisele ei tugine enamasti enda kogemustele. Me kõik omandame kasvamise käigus teatud stereotüübid, illusioonid või ideoloogiad tõlkimise kohta. Üldlevinud arusaamad tõlkijatööst või tõlkimisest ei pruugi aga olla kooskõlas tõlkija tegeliku tööga ja tõlketuru tegelike nõudmistega. Samas võib ka öelda vastupidi: levinud hoiakud on nii tugevad, et tõlketurg ise lähtub osaliselt nendest hoiakutest. Siiski näitab artikli jaoks läbiviidud uuring vastajarühmadevahelisi erinevusi, mis omakorda tähendab, et tudengeid on võimalik mõjutada ning panna tõlkimise konventsioonides kahtlema. Mida täpsemalt on õppejõud kursis tõlketudengite mõtetega tõlkimisest, seda lihtsam on läbi viia arutelusid ja juhtida tudengeid lähemale tõlkijatöö reaalsusele.

Tõlkimisega seotud hoiakutest on kirjutatud palju, näiteks professionaalne tõlkija Chris Durban toob välja hulga nõuandeid alustavatele tõlkijatele, kummutades terve rea levinud arusaamu tõlkijatööst. Muuhulgas rõhutab ta, et tõlkija peaks võtma vastu ainult töid, mille sisust ta detailideni aru saab, või et kakskeelsed inimesed ei ole automaatselt valmis tõlkijad (Durban 2014: 15, 25). Durbani näited lähevad kokku laialt levinud ütlustega tõlkijaameti kohta, nagu tõlkijad on inimesed, kes räägivad ühte või mitut võõrkeelt, või tõlkija tõlgib ükskõik mis valdkonna tekste ükskõik mis teemal, peaasi, et tegemist on võoorkeelega, mida ta valdab, ja tõlkimine käib olematu ajakuluga.

Poola tõlkeuurija Krzysztof Lipiński on koostanud nimekirja üldlevinud hoiakutest tõlkimise kohta ning nimetanud need müütideks:

1) sõnasõnalisuse müüt,

2) tõlkimatuse müüt,

3) nn inetu pardipoja müüt,

4) ühe ja ainukese õige lahenduse müüt,

5) masintõlke müüt,

6) maailma deskriptiivsuse müüt,

7) ühe ja ainsa tõe müüt (Lipiński 2004).

Esimene, sõ n a sõ na li s u s e müüt on tõlkeuurimuses lõputu aruteluteema, kuid üha enam on liigutud arusaama poole, et sõnasõnaline tõlge ei ole võimalik. Samasse kategooriasse võib liigitada ka neljanda müüdi, mis tähendab ühtlasi ka seda, et tõlkijatöö ei seisne ainult sõnaraamatuga töötamises. Tavasti ja Taukari sõnul lähtuvad paljud tõlkijad eeldusest, et eri keelte sõnade vahel on nende tähendusest tulenevad ekvivalentsiseosed, mille põhjal on võimalik otsustada sihtteksti sõnavalikut. Tavast ja Taukar jõuavad aga kiiresti järeldusele, et „sõnadel ei ole selliseid objektiivselt mõõdetavaid parameetreid nagu tähendus, eestikeelsus, sobivus vms. Need on suhtlejate (või suhtluse vaatlejate) parameetrid: mina arvan, et sõna tähendab midagi või sobib mingisse kohta. Kõik suhtluskäitumise valikud põhinevad vältimatult ja olemuslikult subjektiivsetel eelistustel" (Tavast, Taukar 2013: 19, 39). Douglas Robinson kõrvutab omakorda tõlkimist kõnelemisega - mingi tegevusena, mida me teeme sõnade abil. See tähendab, et tõlkija osaleb suhtluses aktiivselt ega ole lihtsalt passiivne keeltevahelise teisendusalgoritmi täitja (Robinson 2003).

Teine müüt ütleb, et mõned tekstid on tõlkimatud, lingvistiliselt või kultuuriliselt liiga spetsiifilised, nii et nende tõlkimist teise keelde ei 
peeta võimalikuks. Tõlkimatuse teema on muidugi palju laiem ja väga palju sõltubki siin just tõlkimise defineerimisest, kuid näiteks Chesterman (1997: 11) ütleb, et „tõlkimine on lõppude lõpuks keelekasutuse üks vorme ja selliselt võttes ei ole mitte miski tõlkimatu, st kõike on võimalik tõlkida kuidagi, teatud piirini, mingil moel, ka sõnamänge on võimalik seletada. Suhtlus ei ole kunagi perfektne, miks peaks siis tõlge seda olema?"3

Kolmas ehk nn inetu pardipoja müüt, nagu Lipiński seda nimetab, on levinud kirjanike ja akadeemikute hulgas. Selle taga on põhimõte, et t õ l g e e i ole (või ei tohiks olla) origin a a list parem, mis omakorda viitab, et tõlkija justkui ei olegi iseseisvalt mõtlev inimene, vaid lihtsalt kopeerib sihtteksti (Lipiński 2004).

Lipiński viies müüt puudutab ma s intõ lget ja lähtub mõttest, et arvutid ning masintõlkeprogrammid on võrdsed inimese toodetud tõlkega. Kõik, kes on masintõlget oma tööks kasutanud, teavad, et inimene on praegu veel võimeline jõudma teistsuguse tulemuseni kui masintõlge. „Inimkeelt kui fikseeritud koodi on masinatele õpetatud alates 1950ndatest ja viimasel ajal on seoses arvutusvõimsuse kiire kasvuga selleks üsna lahedad tingimused, tulemus on aga esialgu niru. Masinad ei suhtle nagu inimesed. Midagi on neile õpetatavas mudelis teistmoodi kui inimsuhtluses" (Tavast, Taukar 2013: 26).

Kuues müüt räägib sellest, et ma ailma e i ole võimalik täieli k u lt kirjeld a d a. Lipiński usub, et keel ainult jutustab maailma ümber, kuid maailm ise eksisteerib väljaspool meid, keelest eraldiseisvana. Maailma ei ole seega võimalik kirjeldada, kuna igaüks meist tajub ja näeb maailma erinevalt. Nii interpreteerib ka iga tõlkija tõlgitavat teksti läbi omaenda vaatenurga, läbi oma arusaama maailmale.

Seitsmes müüt räägib ü h e st j a a in s a st t õ e st, kuid seda on võimalik vaadelda ka kõigi teiste müütide jätkuna ning kokkuvõttena. Ei ole olemas ühte ja ainsat tõde ja ka tõlkimises ei ole ega saa olema ühte ning ainsat tõde (Lipiński 2004).

Chestermani väitel tähendab mingi nähtuse mõistmine seda, et vajame ligipääsu vastavatele mõistetele, vajame kirjeldamis- ja selgitamisoskust (2007: 2). Tõlkijahariduses võiks see tähendada ühtlasi seda, et tudengid õpivad tõlkijatena vastu võtma otsuseid, suudavad olla konstruktiivselt kriitilised ja võimelised enesekriitikaks. Seetõttu on vajalik, et tõlkijad defineeriksid enda jaoks tõlkimise mõiste, mis aitab neil seejärel formuleerida ideoloogia, mis on seotud (võõr)keele, kommunikatsiooni, tähenduse kui sellise, teksti ja teiste tõlkija igapäevatöös oluliste aspektidega.

\section{Uurimus}

Nagu eespool mainitud sai, on tõlkimise definitsioon ajaga palju muutunud. Sõnasõnalisuse, tõlkimatuse ja ekvivalentsuse kontseptsioonide juurest on liigutud funktsionalistlike, kognitiivsete ja kommunikatiivsete lähtekohtade juurde. Teksti uurimise ning lähte- ja sihtteksti ekvivalentsusseoste uurimise kõrval pööratakse üha rohkem tähelepanu tõlkijale ja tõlkeprotsessile.

\footnotetext{
${ }^{3}$ "Translation is, after all, a form of language use; and from this point of view nothing is untranslatable: that is, everything can be translated somehow, to some extent, in some way - even puns can be explained. No communication is perfect, so why should translation be" (Chesterman 1997: 11).
} 
Toimunud muutused on olnud paratamatud ja otseselt seotud tõlketuru kiire muutumisega. Ühtlasi tingisid tõlketuru muutused olukorra, kus vajati eriharidusega spetsialiste. Ehkki ühe ja ainsa tõlkekontseptsiooni olemasolu ei ole võimalik ega ilmselt ka mitte vajalik, on tõlketudengite jaoks kasulik jõuda mingile kindlale arusaamale tõlkeprotsessist ja tõlkijatööst. Kogemused tõlkijate koolitamisel on alles lühiajalised ja pidevalt muutuva tõlketuru tõttu ka väga kiiret ning dünaamilist arengut nõudev valdkond, mistõttu on sellealased uurimused väga vajalikud. Kuna noored tõlkijad ei ole sageli teadvustanud endale, mida tõlkijaamet ja tõlkimine endast kujutab, siis on nende arusaamine tõlkimisest õppejõudude jaoks oluline informatsioon. Tõlkedefinitsiooni ja tõlkimise kui sellise üle mõtlemine aitab tudengitel mõista ka perspektiivide paljusust ja seda, et tõlkimise puhul puudub üks ja ainus tõde, mis on oluline sotsiokonstruktivistlik lähtepunkt.

Käesoleva uurimuse eesmärk on saada teada, kuidas tõlkimist kirjeldatakse ning defineeritakse. Tulemused on abiks tõlkeõppejõududele, sest selgitavad, millistele probleemidele ja lähenemistele tuleks magistriõpingute käigus suuremat tähelepanu pöörata. Ankeetvormis küsitleti kolme gruppi:

1) 61 tudengikandidaati, kes soovisid asuda õppima Tallinna Ülikooli kirjaliku tõlke magistriprogrammis (küsitlus toimus sisseastumiseksamite ajal 2009. aasta juulis);

2) Tallinna Ülikooli kirjaliku tõlke magistriprogrammi kolmanda semestri 15 tudengit (küsitlus toimus detsembris 2009);

3) vähemalt viieaastase töökogemusega professionaalsed - vabakutselised või mõnes asutuses (ka tõlkebüroos) töötavad - tõlkijad, kellel on magistrikraad kirjalikus tõlkes (küsitlus toimus jaanuaris 2010). Kõik selle grupi vastajad olid omandanud magistrikraadi viimase seitsme aasta jooksul ja suurem osa neist on ka Eesti Tõlkemagistrite Liidu liikmed. Välja saadeti 30 küsimustikku ning vastajaid oli 14. Eesti tõlketuru aktiivsust arvestades ei ole tegemist kuigi suure arvuga, kuid kolmanda grupi vastajad valiti välja nende hariduse ja aktiivse töökogemuse järgi.

Küsitlus viidi läbi kirjalikult. Et mitte mõjutada küsitluse tulemusi ega anda vastajale kallutavaid vihjeid, puudusid küsimustikus valikvastused. Kõigile vastajatele esitati küsimus: „Palun kirjeldage mitte rohkem kui viie lausega, mis on teie jaoks tõlkimine."

Vastuseid analüüsiti sisuanalüüsi meetodiga. Sisuanalüüs muudab kvalitatiivsed andmed kvantitatiivseteks ning teeb võimalikuks nende statistilise töötluse. Käesolevas piirdutakse vaid arvandmete esitamisega. Oluline oli vaadata, kas ja mille poolest erinevate gruppide vastused üksteisest erinevad, st uuriti tõlkedefinitsiooni antud ajahetkel. Hüpoteesiks oli, et tõlkijahariduse juba omandanud tõlkijad lähtuvad oma definitsioonis pigem funktsionalistlikest ja kognitiivsetest tõlketeooriatest ning vähese kogemusega ja tõlkijahariduseta tõlkijad pigem sõnasõnalisusest või mõnest teisest levinud arusaamast tõlkimise kohta (nagu neid on välja toonud Lipiński 2004). Küsimustik ei puudutanud suulist tõlget, seda oli selgitatud ankeedi kaaskirjas, tudengikandidaadid said vastava selgituse suuliselt. Seega on eelnevalt ja edaspidi juttu ainult kirjalikust tõlkest.

Sisuanalüüsi põhjal sai vastused jaotada kuude kategooriasse.

1. Tõlkimine on loominguline protsess, nagu kunstiline tegevus.

2. Tõlkimine on loominguline protsess, kuid lähtutakse tõlketeksti funktsioonist. 
3. Tõlkimine on kultuuride vahendamine.

4. Tõlkimine on kahe keele vaheline protsess.

5. Tõlkimine on võõrkeeltega töötamine.

6. Tõlkimine on protsess, mille käigus viiakse lähteteksti mõte üle sihtkeelde.

Allolev graafik näitab horisontaalteljel vastuste jaotumist grupiti ja vertikaalteljel vastajate arvu protsentuaalselt.

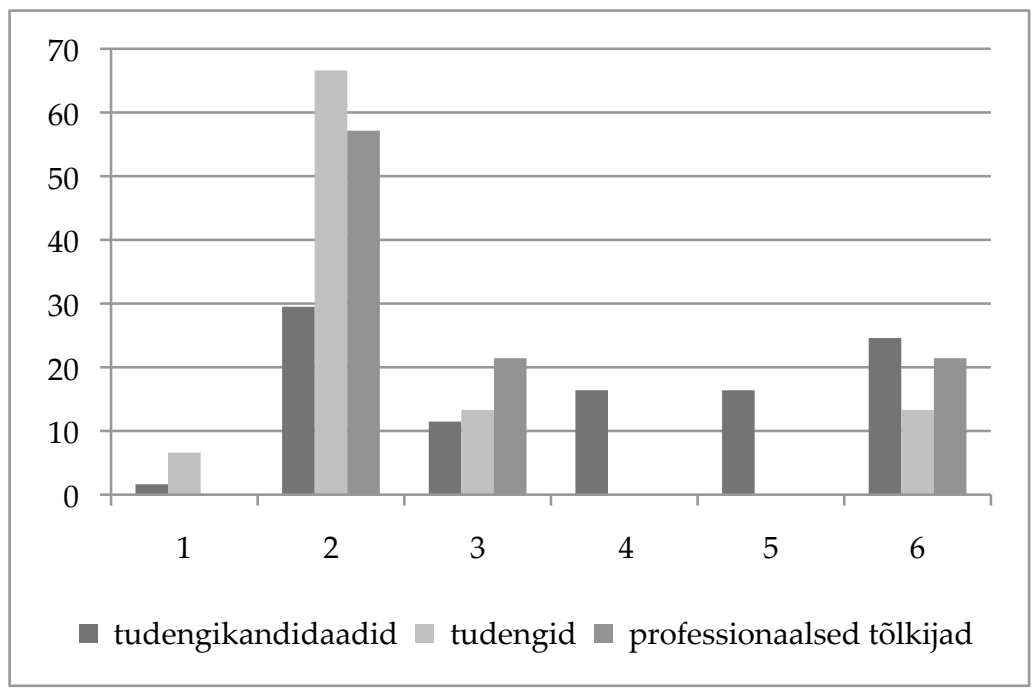

Gra afik 1. Vastusekategooriate jaotumine uurimisgruppides ja vastajate arv protsentuaalselt.

Analüüsides vastusevariante eespool toodud tõlketeoreetiliste lähenemiste järgi, võib öelda, et 2 . vastusekategooria on seotud funktsionalistlike tõlketeooriatega, näiteks skopos-teooriaga, milles on oluline tõlke eesmärk. 2. vastusekategooria oli enim levinud kõigis kolmes vastajate grupis: tudengikandidaatidest vastas nii $29,5 \%$, tudengitest $66,6 \%$ ja professionaalsetest tõlkijatest $57,1 \%$. Kommunikatiivsetele lähenemistele viitab osaliselt vaid 3. vastusekategooria, kus tõlkijat nähakse kultuuride vahendajana, kuid ei mainita tõlkijat kui aktiivset osalejat suhtlusprotsessis (vastajaid vastavalt $11,5 \%, 13,3 \%$ ja 21,4 \%). Nagu graafikust näha, on 3. vastusekategooria kõrgemalt esindatud professionaalsete tõlkijate hulgas.

4. ja 5. vastusekategooria kirjeldavad tõlkimist pigem kui keelelist protsessi, mida tõlkimine kahtlemata osaliselt ka on, kuid vastustest võis näha selget viidet tekstipõhisusele ning lähte- ja sihtteksti (-keele) võrdlemisele, seega ekvivalentsussuhetele. 4. ja 5. vastusekategooria erinevus seisneb selles, et viienda kategooria vastustes mainiti ainult võorkeele tähtsust, kuid neljanda kategooria vastuses oli märgitud ära nii siht- kui ka lähtekeel, kusjuures mitmes vastuses oli sihtkeele tähtsust peetud olulisemaks kui lähtekeele oskust.

Huvitaval kombel ei nimetanud ei tõlketudengid ega ka professionaalsed tõlkijad oma definitsioonides (võõr)keele tähtsust. Tudengikandidaadid on aga 
(võõr)keelte tähtsust nimetanud ja selle põhjal saab välja tuua kõige olulisema erinevuse algajate tõlkijate ning tõlketudengite ja professionaalide vahel. Võib eeldada, et teatud kogemusega tõlkijad, kes on juba lõpetanud või lõpetamas tõlkeõpinguid, peavad keeleoskust küll oluliseks, kuid samas ka enesestmõistetavaks ning keskenduvad oma vastustes tõlkeprotsessi olulisematele komponentidele.

6. vastusekategooria on ainus, milles võib leida seoseid ka kognitiivsete lähenemistega. Eespool sai mainitud, et suhtlus ei ole iseenesest kunagi perfektne, seega lähteteksti koostaja poolt sõnumisse kodeeritud mõtte ülekandmiseks peab tõlkija lahendama probleeme, konstrueerima tähendusi ja kasutama tõlkimisel teadlikult erinevaid strateegiaid. 6. vastusekategooria oli kõigis gruppides järjestuselt teine.

Vaid kaks inimest tudengikandidaatide ja tudengite seast nimetas tõlkimist loominguliseks protsessiks, nagu seda on kunsti tegemine. Selline tulemus on pisut üllatav, kuna minu kui tõlkeõppejõu kogemus tudengikandidaatidega suhtlemisel on pigem viidanud, et tõlkimisest mõeldakse peamiselt kui ilukirjanduslikust tõlkimisest ja sellega seoses samastatakse tõlkimist kunstiliselt loomingulise protsessiga. Kuna ilukirjanduse tõlkimisel on traditsiooniliselt toetutud ekvivalentsusteooriatele, siis võib ka siin eeldada, et tõlkimist nähakse pigem tekstidele keskenduva tegevusena ja vähem pööratakse tähelepanu näiteks protsessile ja eesmärgile.

Kui võrrelda tulemusi Lipiński (2004) sõnastatud tõlkimise hoiakutega, jääb silma sõnasõnalisuse müüt, mille puhul tõlkijad eeldavad, et eri keelte sõnade vahel on nende tähendusest tulenevad ekvivalentsusseosed (4. ja 5. vastusekategooria). Viiteid Lipiński sõnastatud hoiakule, et maailma ei ole võimalik täielikult kirjeldada, sest igaüks tajub ja näeb seda erinevalt, võib leida 6. kategooria vastuste hulgast. Selles kategoorias liiguti küll eemale tekstikesksest lähenemisest ja kognitiivsete arusaamade suunas, kuid esialgu jäi siiski kõlama seisukoht, et lähteteksti koostaja mõte on teksti lugedes üheselt selge ja seda on võimalik ilma probleemideta samatähenduslikult tõlkida.

\section{Kokkuvõte}

Küsitluse järeldusena võib öelda, et tudengite ja professionaalide vastuste vahel suuri erinevusi ette ei tulnud. Erinevusi oli aga tudengikandidaatide ja professionaalsete tõlkijate või tõlkijaharidust omandavate tudengite vahel. Kõige suurem erinevus on suhtumine (võõr)keele rolli tõlkimisel. (Võõr)keele mittenimetamine viitab sellele, et juba kogenud tõlkijad ei pea seda kõige olulisemaks tõlkimise komponendiks, vaid keskenduvad pigem tõlke eesmärgile ja ka tõlkeprotsessile. Küsitlustulemused täiendavad väidet, et tõlkija on loov inimene, mitte mehaaniline tekstide transkodeerija (Lederer 2003). Seda näitab tulemus, mille kohaselt $21,4 \%$ professionaalsetest tõlkijatest peab tõlkimist protsessiks, mille käigus toimub lähteteksti mõtte üleviimine sihtkeelde, ja suurem osa $(57,1 \%)$ professionaalsetest tõlkijatest on seda meelt, et tõlkimine on loominguline protsess, mille puhul lähtutakse tõlketeksti funktsioonist. Tõlkijahariduse seisukohalt võime näha, et tudengid liiguvad lähteteksti sõnasõnalise teisendamise juurest sihtkultuuris funktsioneeriva teksti kirjutamise suunas. Seega võib öelda, et tõlkimise olemust on õpingute ja tõl- 
kimise käigus teistmoodi mõtestama hakatud ning üldlevinud hoiakuid esineb tõlkimise defineerimisel vähem. Tõlkeõppejõudu aitavad niisuguse küsitluse tulemused paremini mõista, millele tuleks tudengitega töötades rohkem tähelepanu pöörata.

\section{Kirjandus}

A n g e l o n e, Erik 2010. Uncertainty, uncertainty management and metacognitive problem solving in the translation task. - Translation and Cognition. (American Translators Association Scholarly Monograph Series XV.) Toim Gregory M. Shreve, E. Angelone. Amsterdam: John Benjamins Publishing Company, lk 17-40.

Chesterman, Andres 1997. Memes of Translation. (Benjamins Translation Library 22.) Amsterdam-Philadelphia: John Benjamins Publishing Company.

$\mathrm{C}$ h e s t e r m a n, Andrew 2007. On the Idea of a Theory. - Across Languages and Cultures, kd 1, nr 8, lk 1-16.

D u r b a n, Chris 2014. 101 Things a Translator Needs to Know. WLF Think Thank.

Gonzáles Davies, Maria 2004. Undergraduate and postgraduate degrees: Aims and expectations. - Translation in Undergraduate Degree Programmes. (Benjamins Translation Library 59.) Toim K. Malmkjær. Amsterdam-Philadelphia: John Benjamins Publishing Company, lk 67-81.

$\mathrm{H}$ at zi d a ki, Anna 2007. The process of comprehension from a psycholinguistic approach. - Implications for Translation. Meta: journal des traducteurs / Meta: Translators' Journal, kd 1, nr 52, lk 13-21.

$\mathrm{K}$ a s k, Katrin 2011. Arusaamine tõlkeprotsessis ja seda mõjutavad tegurid. Magistritöö. Tartu Ülikool. Filosoofiateaduskond. http://hdl.handle.net/10062/17953 (4. XII 2014).

Kira ly, Don 2000. A Social Constructivist Approach to Translator Education. Empowerment from Theory to Practice. Manchester-Northampton: St. Jerome Publishing.

Lederer, Marianne 2003. Translation. The Interpretive Model. Tlk Ninon Larché. Manchester-Northampton: St. Jerome Publishing.

Li p i ń s k i, Krzysztof 2004. Mity Przekładoznawska. - http://transubstantiation. wordpress.com/2008/11/02/myths-of-translation-i/, http://transubstantiation. wordpress.com/2008/11/09/myths-of-translation-ii/ (26. I 2014).

N o r d, Christiane 2001. Translating as a Purposeful Activity. Manchester-Northhampton: St. Jerome Publishing.

P a n o u, Despoina 2013. Equivalence in translation theories: A critical evaluation. - Theory and Practice in Language Studies, kd 3, nr 1, lk 1-6.

$\mathrm{P}$ a p p e 1, Triin, F a l k, Tiia 2012. Study diaries in translation education at Tallinn University. - Eesti Rakenduslingvistika Ühingu aastaraamat, nr 8, lk 185-194.

P y m, Anthony 2007. On History in Formal Conceptualization of Translation. Across Languages and Cultures, kd 2, nr 8, lk 153-166.

R e is s, Katharina, V e r m e e r, Hans J. 1984. Grundlegung einer allgemeinen Translationstheorie. Tübingen: Niemeyer.

R o b i n s o n, Douglas 2003. Performative Linguistics: Speaking and Translating as Doing Things with Words. Florence, KY: Routledge. 
T a va st, Arvi, T a u k a r, Marju 2013. Mitmekeelne oskussuhtlus. Tallinn: Valgus.

V a ld eón, Roberto A. 2010. Translation in the informational society. - Across Languages and Cultures, kd 11, nr 2, lk 149-160.

V a l d r e, Andres 2004. Inglise-eesti tehnikatõlke vigade liigid ja põhjused. - Eesti Rakenduslingvistika Ühingu aastaraamat, nr 1, lk 187-207.

V i n a y, J. P., D a r b e l n e t, J. 1995. Comparative Stylistics of French and English: A Methodology for Translation. Amsterdam-Philadelphia: John Benjamins.

\section{Attitudes towards translation, or how translation is defined}

Keywords: translation, translator education, attitudes towards translation

The article addresses the available definitions and interpretations of translation, mainly in view of translator education. The constantly changing market as well as the modern information society requires that a translator should be flexible and ready to act in a constructive manner whatever the situation. Knowing just a few basics is hardly enough if a translator's ambition is higher than the lowest market segment, let alone job satisfaction. Therefore, I would argue that it is crucial for translators to reach their own definition of translation and to be able to analyse the translation process.

Translation is a field of many well-established attitudes. Often students begin their studies with an entrenched idea of translation, which instead of their personal experience is based on some stereotypical views of the field. Such fixations, however, may prove an inhibiting factor in the development of translator education.

The article introduces the analysis of a questionnaire applied to professional translators, translation students and applicants for translation studies in order to find out their definition of translation. The results should be helpful to would-be translators as well as to translation teachers.

Triin van Doorslaer (former Pappel, b.1972), MA, Tallinn University, PhD Student, KU Leuven (Belgia) Translation Studies Bibliography / Handbook of Translation Studies, Project Assistant, triin.van_doorslaer@tlu.ee 